\title{
Beneficial effects of long-term beta-blockade in congestive cardiomyopathy
}

\author{
KARL SWEDBERG, ÅKE HJALMARSON, FINN WAAGSTEIN, \\ INGEMAR WALLENTIN
}

From the Departments of Medicine I and Clinical Physiology, Sahlgren's Hospital, University of Göteborg,
Göteborg, Sweden

SUMMARY Twenty-eight patients with heart failure caused by congestive cardiomyopathy, which had been diagnosed according to the criteria of Goodwin and Oakley, were treated with beta-blocking agents for six to 62 months, except for four patients who died within two months. Repeated non-invasive investigations were performed before and during treatment as well as exercise tests and chest $x$-rays. The echocardiographic and pulse curve findings indicated an improvement in systolic and diastolic myocardial function. The ejection fraction increased from $0.32 \pm 0.02$ to $0.42 \pm 0.04$, and the third heart sound amplitude and rapid filling wave were significantly reduced. The functional classification improved in 15 patients while in 12 patients it remained unchanged and in one it deteriorated. During follow-up, 10 patients died, most of them suddenly. The mortality was lower than expected in this severely ill group of patients.

The beneficial effect of chronic beta-blockade in patients with congestive cardiomyopathy suggests that catecholamines are involved in the pathogenesis of congestive cardiomyopathy, and that patients with congestive cardiomyopathy may have inappropriate sympathetic cardiac stimulation which can be reduced by chronic beta-blockade. It is suggested that beta-receptor blockade should be added to conventional treatment with digitalis and diuretics in all patients with severe myocardial failure caused by congestive cardiomyopathy.

Patients with congestive cardiomyopathy (COCM) are usually treated with digitalis and diuretics for relief of heart failure. The prognosis is considered poor when heart failure is severe despite optimal conventional treatment. ${ }^{1-4}$ Temporary improvement of heart failure has been reported after very long periods of bed rest. ${ }^{5}$ In 1975 Waagstein et al. ${ }^{6}$ reported from this clinic that seven patients with COCM and heart failure showed improved myocardial function and exercise capacity on chronic beta-receptor blockade.

This study was undertaken to evaluate further the effects of beta-blockade in patients with COCM. Twenty-eight patients were treated with betablocking agents for six to 62 months, except four patients who died within two months. Their myocardial function was assessed before the start of treatment and repeatedly thereafter by standard non-invasive investigations at the department of clinical physiology including echocardiography and pulse curves. Since repeated assessment of cardiac Received for publication 13 August 1979 function was planned in this study, invasive investigations were judged unethical. Cardiac catheterisation was performed in only four of the early patients enrolled in the study. Coronary angiography was performed in 14 other patients, in each case without pathological findings. None of the patients included in this study had a history of coronary artery disease.

\section{Patients}

Twenty-eight patients ( 21 men and seven women, aged 16 to 60 years, mean age 46 years) were included in the study. All were diagnosed as having COCM according to the criteria proposed by Goodwin and Oakley, ? that is a heart muscle disorder with depressed systolic function without known cause. Patients were not included if there was a history of coronary artery disease or abnormal coronary angiography; none had a history of alcohol abuse or systemic disease. All patients gave a history of dyspnoea, its duration varying from 
three to 172 months (median value 12 months), despite treatment with digitalis and diuretics. The details of patients are summarised in Table 1. Twenty-seven of the patients entered an observation period of at least one month, with the dosage of digitalis and diuretics unchanged before starting beta-blockade or placebo treatment. One patient, a 16-year-old girl (case 20), deteriorated during the first two weeks of observation and a beta-blocker was given because of concern for her condition. The first eight patients started on beta-blockade immediately after the observation period and then were followed up regularly. Five of these patients the 16 patients, placebo treatment was continued for three months. Two patients (cases 11 and 16) were given beta-blockers before the end of this three-month period, because of severe deterioration in their condition, and three others continued on placebo for six months to enable one to assess the stability of theirs.

\section{BETA-BLOCKER TREATMENT}

In six of the seven patients first treated with beta blockers the cardioselective agent practolol was used. It was thought on theoretical grounds that a cardioselective drug, with less influence on peri-

Table 1 Patients with congestive cardiomyopathy treated with chronic beta blockade as well as digitalis and diuretics

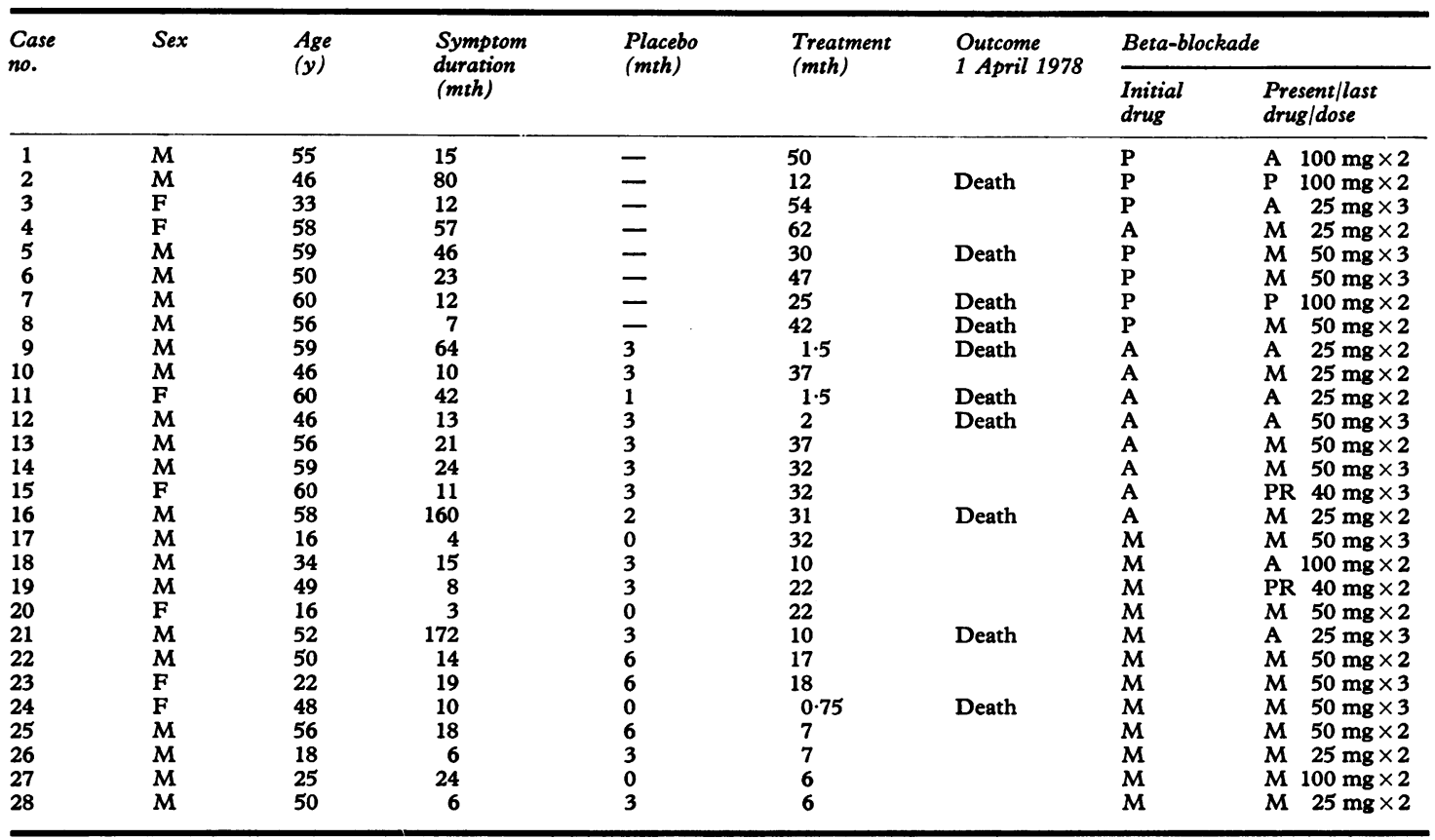

A, alprenolol; M, metoprolol; P, practolol; PR, propranolol.

Symptom duration is until start of treatment with beta-blockade or placebo.

were included in our previous paper. ${ }^{6}$ For the remaining 20 patients (cases 9 to 28) the intention was, after the initial observation period, to give all of them single-blind placebo treatment for three months before starting beta-blockade. However, this plan could only be followed in 16 patients. Four patients (cases 17, 20, 24, and 27), because their condition was considered to be life-threatening, were given beta-blockers as above and no placebo. The procedure allowed the placebo period to be prolonged if, during it, signs of haemodynamic improvement could be seen, as judged by the noninvasive investigations mentioned above. In 11 of pheral vascular resistance, should have advantages over non-selective beta-blockers, with their attendant risk of unmasking alpha-receptor-induced vasoconstriction. However, one of the first patients was treated with the non-selective agent alprenolol, which produced the same response as practolol did in the others. After this observation, alprenolol was given to the next nine patients enrolled in the study in doses varying between $25 \mathrm{mg}$ three times daily and $100 \mathrm{mg}$ twice a day. Because of difficulties experienced in increasing the alprenolol dose, and also because there were three early deaths (cases 9 , 11 , and 12) in this group, all patients were changed 
from alprenolol to metoprolol treatment within six months. With great differences in response between patients, difficulties were anticipated in the evaluation of the importance of cardioselectivity and the last 12 patients included in the study all received metoprolol from the start of treatment. The usual initial dose of metoprolol was $25 \mathrm{mg}$ a day which could be increased by $25 \mathrm{mg}$ each day or every second day. In three patients (cases 17, 20, and 28) whose clinical condition was extremely poor, the initial dose was $12.5 \mathrm{mg}$ a day and it was increased slowly, by 12.5 to $25 \mathrm{mg}$ every second or third day. Systolic blood pressure and resting heart rate were measured five to six times a day, the aim of treatment being a blood pressure above $100 \mathrm{mmHg}$ and a heart rate of 70 beats per minute. The duration of beta-blocker treatment, the initial drug used, and the final drug and dosage are given in Table 1 for all of the patients.

\section{Methods}

\section{NON-INVASIVE INVESTIGATIONS}

Investigations were performed according to a standard procedure in all patients, usually at the same time each day. Because it was possible to perform these investigations on several occasions during the follow-up period, myocardial function could be repeatedly assessed. Investigations included phonocardiograms from five standard areas, an apex cardiogram, pulse tracings from the carotid artery, jugular vein, and liver, and an echocardiogram. All records, with the exception of the echocardiogram, were made using an eight-channel ink-recorder (Mingograph 81, Elema-Schönander) at a paper speed of $100 \mathrm{~mm} / \mathrm{s}$. The phonocardiograms were recorded with an acceleration microphone (Elema-Schönander EMT 25C) fixed to the thoracic wall with adhesive tape. The amplitude of the third and fourth heart sounds was measured from the apical recording in the 25 or $50 \mathrm{~Hz}$ band with an amplification of $1 / 10$, using the mean value of three beats. The apex cardiogram and the pulse tracings were all performed with a hand-held funnel-shaped pick-up, internal diameter $2.5 \mathrm{~cm}$, connected to a crystal transducer (Elema-Schönander EMT 510C) by a $35 \mathrm{~cm}$ latex tube. This combined system had a time constant of 1.9 to 4.6 seconds (depending on the individual amplification used for each curve) and a frequency response of at least 0.08 (at a time constant of 1.9 seconds) to $65 \mathrm{~Hz}^{8}$ Left ventricular ejection time was measured from the carotid pulse and corrected for heart rate according to the method of Meiners. ${ }^{910}$ This technique expresses left ventricular ejection time as a percentage of the normal left ventricular ejection time for the actual heart rate. The apex cardiogram was recorded with the patient in the left lateral position. The " $a$ " wave and the rapid filling wave (RFW) were expressed as a percentage of the total amplitude of the pulse curve $(\mathrm{H})$. All measurements were calculated as the mean of values from at least three cardiac cycles.

A commercially available ultrasonoscope (Ekoscan 30, Mediscan) was employed for echocardiography, using a $2.25 \mathrm{MHz}$ transducer, with $10 \mathrm{~cm}$ focus and a repetition rate of 1000 impulses/second. Before 1975, polaroid photographs of the time motion display were taken from a slave storage oscilloscope (Textronix 603). From 1975 a fibreoptic recorder was used in all investigations (Honeywell Visicorder 1856).

Stroke volume was calculated from the enddiastolic and end-systolic volumes, derived by the cube method, ${ }^{11}$ and the ejection factor (EF) from the stroke volume and end-diastolic volume. The mean velocity of circumferential fibre shortening (mean $\mathrm{V}_{\mathrm{CF}}$ ) was calculated according to the method of Cooper et al.,12 except that left ventricular ejection time in the formula was derived from the carotid pulse curve.

All data were summarised in a report which included both the diagnosis and an evaluation of the severity of myocardial dysfunction. The diagnosis of congestive cardiomyopathy was based on the finding of a dilated left ventricle with symmetrically depressed systolic function, without hypokinetic areas to suggest coronary artery disease. The severity was assessed by a combination of direct measurements of pump function (EF and mean $\mathrm{V}_{\mathrm{CF}}$ ), and indirect evidence of forward and backward failure.

The principles used in assessing the degree of myocardial dysfunction are based on earlier experience and are described below. In mild to moderately severe myocardial dysfunction, with left ventricular end-diastolic diameter (LVEDD) around 5.5 to $7.0 \mathrm{~cm}$, EF 0.40 to 0.60 , and mean $V_{C F} 0.70$ to 1.00 , pump function seems to be adequate, at least at rest, and there are often no signs of disturbed diastolic function. In more severe cases of congestive cardiomyopathy with LVEDD between 7 and $10 \mathrm{~cm}, \mathrm{EF}<0.40$, and mean $\mathrm{V}_{\mathrm{CF}}<0 \cdot 70$, diastolic function is also disturbed to a varying degree. At this stage, signs of decreased distensibility and backward failure occur. When the left ventricle is resistant to filling because of wall and/or volume stiffness, the most important compensatory mechanism is a strengthening of atrial contraction producing an increased atrial contribution to diastolic inflow. This increased atrial contraction produces a pathological fourth 
heart sound and an $\mathrm{a} / \mathrm{H}$ ratio $>15$ per cent, and a moderate enlargement of the left atrial anteroposterior diameter frequently occurs. In most cases of severe COCM, however, this compensatory increase in atrial contraction is not sufficient to create an adequate stroke volume. With decreasing stroke volume, the left ventricular ejection time falls below 90 per cent. If cardiac output then becomes inadequate, signs of stasis and backward failure appear as a third heart sound, a pathological rapid filling wave in the apex cardiogram, a reinforced pulmonary component of the second heart sound, and, sometimes, dilatation of the right heart with signs of tricuspid regurgitation in the jugular and hepatic tracings. At each level of decompensation complementary findings are seen by the different techniques and the degree of decompensation can thus be established by several criteria. For example, the pulmonary and tricuspid valve movements usually change in pulmonary hypertension and the mitral valve motion mirrors different degrees of obstruction to ventricular filling, supporting the evidence of the diastolic extra sounds and the shape changes of the apex curve. With a severe degree of backward failure the left atrium dilates further, but, as the contractile force usually diminishes, the fourth heart sound and the $\mathrm{a} / \mathrm{H}$ ratio may return to normal. This is in these cases a pathological change. In contrast, if myocardial function improves, with less distension of the left atrium, pathological values may reappear.

When the left ventricle is severely dilated with an LVEDD of about 8 to $10 \mathrm{~cm}$, secondary mitral regurgitation usually occurs. Since the resistance to ventricular emptying then falls because of regurgitation into the left atrium, this can result in an increase in the $\mathrm{EF}$ and mean $\mathrm{V}_{\mathrm{CF}}$, giving a false impression of improved systolic myocardial function. Changing degrees of mitral regurgitation are a real problem in the evaluation both of different patients and in the longitudinal follow-up of single individuals. If, for example, the patients respond to treatment and the degree of mitral regurgitation decreases or disappears, the EF and mean $V_{C F}$ may decrease giving the impression of deteriorating myocardial function. The EF and mean $V_{C F}$ can therefore be misleading if used in isolation and must be complemented by measurement of LVET and the whole battery of signs of backward failure to be properly interpreted in cases of severe cardiomyopathy.

\section{EXERCISE TESTS}

Dynamic exercise was performed seated, using an electromagnetically braked bicycle (Siemens-Elema AB). The workload was increased by 20 watts every two minutes until exhaustion or haemodynamically important arrhythmias developed. The electrocardiogram was recorded continuously through chest-head leads. Blood pressure was measured by the cuff method. Work-pulse was calculated according to the equation:

$$
\frac{\text { Workload }(\text { watt }) \times 60}{\text { Heart rate } / \text { minute }}=\text { joules } / \text { beat }
$$

\section{INVASIVE INVESTIGATIONS}

Only four of the patients (cases $1,2,6$, and 7) were catheterised as part of the clinical evaluation before and during beta-blockade. As repeated investigations were planned, non-invasive techniques were used thereafter. Catheterisations were performed at rest in the supine position without premedication. Pulmonary pressures were recorded by a Cournand catheter and arterial pressures by a polyethylene catheter in the brachial artery. Pressures were recorded through Statham $23 \mathrm{Db}$ transducers and Honeywell amplifiers and registered on ultraviolet paper. The reference level was $5 \mathrm{~cm}$ below the sternum. Cardiac output was determined by the direct Fick principle or by the indicator dilution technique. Selective coronary and left ventricular angiograms were performed in 14 of the older patients and all coronary angiograms were normal.

\section{STATISTICS}

Comparison before and during treatment has been made with Student's $t$ test for paired observations. In the text the mean values $\pm S E M$ are given.

\section{Results}

\section{CLINICAL FINDINGS}

Twenty-eight patients were studied before treatment, and with up to 62 months of chronic beta blockade. As can be seen from Table 1, the duration of symptoms before treatment varied from three to 172 months. The treatment period equalled or exceeded six months in 24 patients, and was shorter than this in four patients who died early. In all patients, a low dose of a beta-blocking agent was given initially because of the risk of inducing heart failure. The maintenance doses used are shown in Table 1.

From Table 2 it can be seen that, in terms of functional group, 15 patients improved, 12 were unchanged, and one patient deteriorated. The improvement seen was not related to the patients' initial functional group nor to the duration of pretreatment symptoms. A very pronounced improvement occurred in cases $1,4,10,16,17,20$, and 22 , 
Table 2 Functional grouping according to New York Heart Association criteria before and during treatment with beta-blockers

\begin{tabular}{|c|c|c|c|c|c|c|c|c|}
\hline \multirow{2}{*}{$\begin{array}{l}\text { Case } \\
\text { no. }\end{array}$} & \multirow{2}{*}{$\begin{array}{l}\text { Functional } \\
\text { group }\end{array}$} & \multicolumn{7}{|c|}{ Months after start of beta-blockade } \\
\hline & & 1 & 3 & 6 & 12 & 18 & 24 & 36 \\
\hline 1 & IV & III & III & III & II & II & II & II \\
\hline 2 & III & III & III & III & $t$ & & & \\
\hline 3 & III & III & III & III & III & III & III & III \\
\hline 4 & III & III & III & II & II & II & II & II \\
\hline 5 & IV & III & III & III & III & III & III & $t$ \\
\hline 6 & III & III & III & III & III & III & IV & III \\
\hline 7 & III & III & III & III & III & III & III & $t$ \\
\hline 8 & III & III & III & III & II & II & III & III \\
\hline 9 & III & III & $t$ & & & & & \\
\hline 10 & III & IV & II & II & I & I & I & II \\
\hline 11 & IV & $t$ & & & & & & \\
\hline 12 & III & III & $\dagger$ & & & & & \\
\hline 13 & III & III & III & II & II & II & II & II \\
\hline 14 & III & III & III & II & II & II & II & II \\
\hline 15 & III & III & III & III & III & III & III & III \\
\hline 16 & IV & III & III & III & II & II & II & $t$ \\
\hline 17 & IV & III & II & II & II & II & I & \\
\hline 18 & III & III & III & III & III & & & \\
\hline 19 & III & III & III & III & III & III & & \\
\hline 20 & IV & III & II & I & I & I & & \\
\hline 21 & III & III & III & III & $t$ & & & \\
\hline 22 & III & III & II & II & I & I & & \\
\hline 23 & II & II & I & I & & & & \\
\hline 24 & III & $t$ & & & & & & \\
\hline 25 & III & III & III & III & & & & \\
\hline 26 & III & III & III & II & & & & \\
\hline 27 & IV & II & II & II & & & & \\
\hline 28 & IV & III & III & III & & & & \\
\hline
\end{tabular}

$t=$ dead.

and five of these returned to full-time work (cases $10,16,17,20$, and 22). Three of the patients showed a dramatic improvement (cases 1, 17, and 20 ) in their clinical condition, and two of those (cases 17 and 20) are described in detail in the case reports while case 1 is described elsewhere. ${ }^{13}$

During the follow-up period 10 patients died, seven of them without showing clinical deterioration after the start of beta-blockade (cases 2, 7, 8, 9, 12, 21, and 24; Table 2). Two patients died after their clinical condition had improved as a result of more than two years' treatment (cases 5 and 16). One patient deteriorated gradually after the start of beta-blockade, treatment was discontinued after five weeks, and she died one week later (case 11). In none of the other nine patients was the addition of beta-blockade to their conventional treatment considered to have increased their cardiac decompensation. Seven of the patients died suddenly and three died from cardiac decompensation. Four of the 10 patients died within three months of starting beta-blockade, and three of these died suddenly (cases 10,12 , and 24 ).

\section{Case reports}

The clinical course is illustrated by the following three cases.

\section{CASE 17}

This was a 16-year-old boy who developed a throat infection in March 1975. He recovered in a week but 10 days later he again became febrile and a chest $x$-ray showed cardiomegaly $\left(800 \mathrm{ml} / \mathrm{m}^{2}\right)$ and bronchopneumonia. He was treated with digoxin and frusemide at another centre for one month. Repeated blood cultures were negative and his fever disappeared in a few days. The patient's clinical condition remained unchanged during the first month as did his cardiac enlargement. He was readmitted to the hospital three-and-a-half months after the first admission, giving a one-week history of increasing exertional dyspnoea and gastrointestinal discomfort. $\mathrm{He}$ was referred to our hospital 10 days later, four months after cardiomegaly was first noted. On admission he was breathless at rest. Auscultation showed a third heart sound, gallop rhythm, and an apical systolic murmur. The blood pressure was $110 / 80 \mathrm{mmHg}$ and the heart rate 120 beats/min. Investigations (Table 3) gave the following results: LVEDD $8 \cdot 3 \mathrm{~cm}$, EF $0 \cdot 16$, LVET 73 per cent, a loud third heart sound, and much increased rapid filling wave ratio. Cardiac volume was $950 \mathrm{ml} / \mathrm{m}^{2}$. Over the following week his condition deteriorated with increasing dyspnoea, peripheral cyanosis, and hypotension, and treatment with metoprolol $10 \mathrm{mg}$ three times a day orally was started in addition to the digoxin and frusemide. Over the following days, his heart rate decreased from 110 beats/min to 85 to 90 beats/min and the blood pressure increased to $110 / 90 \mathrm{mmHg}$. However, nocturnal dyspnoea persisted during this time. During the second week, the metoprolol dose was slowly increased to $25 \mathrm{mg}$ three times a day, and the patient's clinical condition improved gradually thereafter, with reduced dyspnoea. After seven weeks he was taking $125 \mathrm{mg}$ a day of metoprolol and investigations indicated a slight improvement, with EF 0.25 and diminished extra sounds but unchanged LVEDD of $8.2 \mathrm{~cm}$. Over the following months, the patient was able to resume work at his father's farm. Repeated investigations six months later showed a further improvement in myocardial function. The LVEDD had decreased to $7.5 \mathrm{~cm}$, and the EF was 0.37 . The LVET was 85 per cent and there were faint extra sounds but the apical systolic murmur remained. The cardiac volume at this time was $650 \mathrm{ml} / \mathrm{m}^{2}$. The patient was able to work to up to 160 watts on a bicycle ergometer. This improvement continued and one year after the start of beta-blockade the patient was in full-time work at the farm. A further investigation two-and-a-half years after the start of treatment (Table 3) disclosed an LVEDD of $8.2 \mathrm{~cm}$, an EF 
Table 3 Results from first non-invasive investigation before $(C)$, and last investigations during (B) beta-blockade in 28 patients with congestive cardiomyopathy

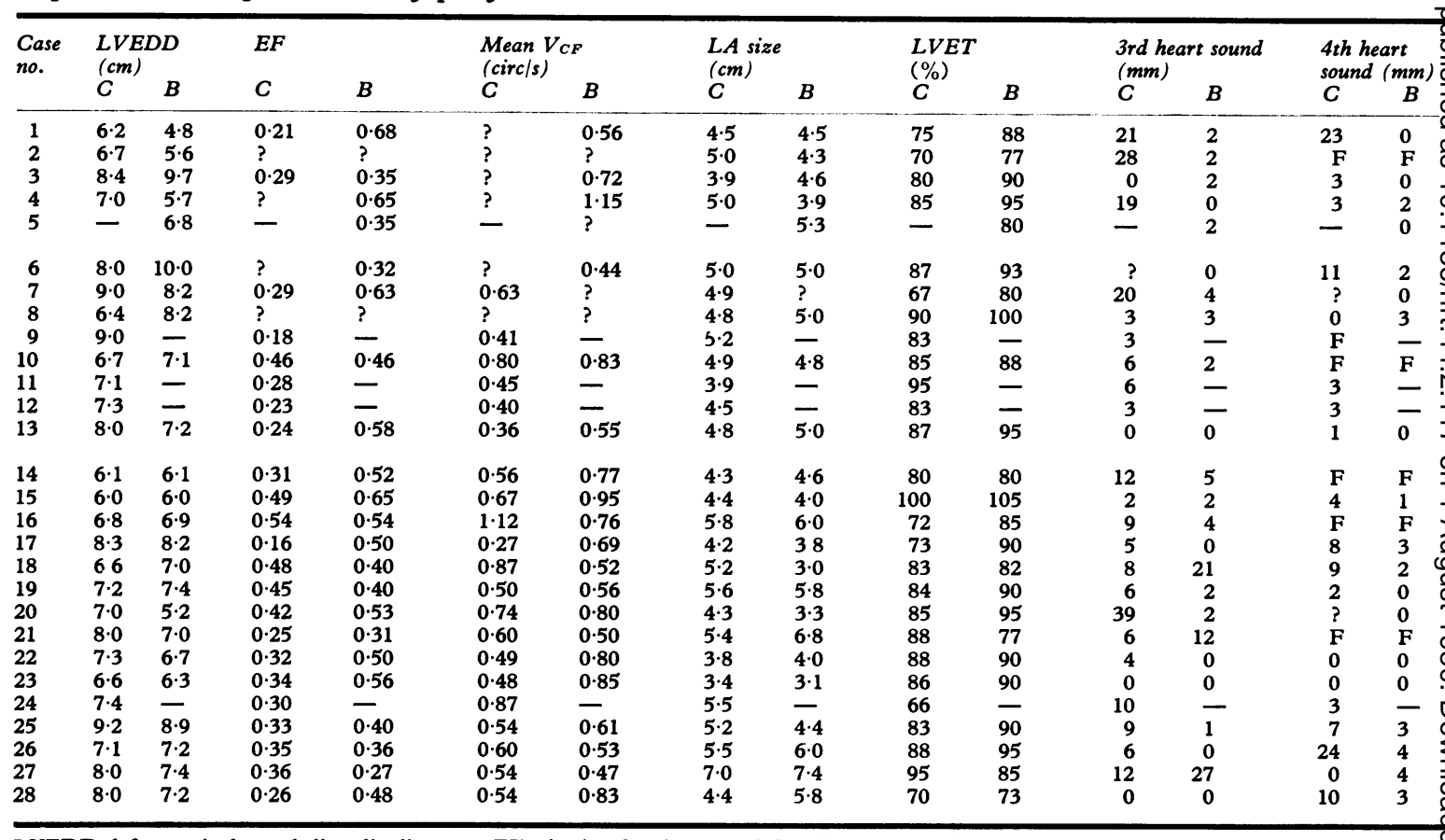

LVEDD, left ventricular end-diastolic diameter; EF, ejection fraction; LA, left atrium; LVET, left ventricular ejection time; RFW, rapid filling wave.

of 0.50 , and LVET of 90 per cent, a faint third heart sound, and an apical systolic murmur. The patient had a normal working capacity.

\section{CASE 20}

This was a 17-year-old girl who had had bronchial asthma since childhood. Despite this, she had worked as a groom for 10 months, and was receiving treatment with terbutaline by inhalation. For three months before admission, she had suffered from increasing exertional dyspnoea, and for the last month from epigastric discomfort. On admission in May 1976 she was dyspnoeic but without peripheral oedema or pulmonary râles. There was significant hepatic enlargement. On auscultation a third heart sound and a weak apical systolic murmur could be heard. The heart rate was 140 beats/min (LVEDD $7 \cdot 1 \mathrm{~cm}$, EF 0.35, LVET 55\%). Treatment with digoxin and frusemide was started. Five days later the patient's condition had improved but she was still in functional group IV. Investigations (Fig. 1; Table 3) showed an LVEDD of $7.0 \mathrm{~cm}$, an EF of 0.42 , an LVET of 85 per cent, and a loud third heart sound, an increased $\mathrm{RFW} / \mathrm{H}$ ratio, and a weak mitral regurgitation murmur. One week later her condition was unchanged. Cardiac catheterisation showed an arterial pressure of $80 /$ $57 \mathrm{mmHg}$, a pulmonary artery pressure of $42 / 26$ $\mathrm{mmHg}$, and a wedge pressure of $27 \mathrm{mmHg}$. The cardiac index was $1.7 \mathrm{l} / \mathrm{min}$ per $\mathrm{m}^{2}$ and the stroke index $17 \mathrm{ml} / \mathrm{m}^{2}$. After metoprolol $10 \mathrm{mg}$ intravenously, cardiac output decreased acutely from $2 \cdot 7$ to $2 \cdot 1$ litres while pressure recordings were essentially unchanged.

Treatment with metoprolol $12.5 \mathrm{mg}$ orally three times a day was started, the dose being increased to $125 \mathrm{mg}$ daily within two weeks as her clinical condition improved. The heart rate was 100 to 110 beats/min during this period. Repeated investigations showed a much reduced third heart sound but otherwise unchanged results. During the next month there was a steady improvement in her condition, with diminished dyspnoea and heart rate and an increased blood pressure. Frusemide was withdrawn. Two months after the start of beta blockade the patient could manage ordinary activities without distress. Investigations at this time showed an LVEDD of $6.4 \mathrm{~cm}$, an EF of 0.48 , a much reduced third heart sound and $\mathrm{RFW} / \mathrm{H}$ ratio, and no apical murmur. One month later she was free of exertional dyspnoea and resumed work. Her asthma was controlled without difficulty on 


\begin{tabular}{|c|c|c|c|c|c|c|}
\hline \multicolumn{2}{|c|}{$R F W / H$ ratio } & \multicolumn{2}{|c|}{$\begin{array}{l}\text { a/H ratio } \\
(\%)\end{array}$} & \multicolumn{3}{|c|}{ Mitral regurgitation } \\
\hline$C$ & $B$ & $C$ & $B$ & $C$ & $B$ & \\
\hline 17 & 10 & 10 & 10 & Yes & No & \\
\hline 19 & 0 & F & F & Yes & No & \\
\hline 18 & 6 & 26 & 14 & Yes & Yes & \\
\hline 37 & 4 & 10 & 10 & No & No & \\
\hline - & 9 & - & 12 & No & - & $\begin{array}{l}\text { (Not investigated } \\
\text { before) }\end{array}$ \\
\hline 39 & 0 & 53 & 18 & $?$ & No & \\
\hline 14 & 5 & $?$ & $?$ & Yes & Yes & \\
\hline 11 & 4 & 32 & 34 & Yes & Yes & \\
\hline 13 & - & $\mathbf{F}$ & - & Yes & - & (Died) \\
\hline 15 & 3 & $\mathbf{F}$ & F & No & No & \\
\hline 16 & - & 30 & - & Yes & - & (Died) \\
\hline 16 & - & 48 & - & No & - & (Died) \\
\hline- & - & - & - & No & No & $\begin{array}{l}\text { (Apex curve not } \\
\text { obtained) }\end{array}$ \\
\hline 12 & 2 & F & $\mathbf{F}$ & No & No & \\
\hline 8 & 8 & 14 & 12 & No & No & \\
\hline 15 & 2 & $\mathrm{~F}$ & F & Yes & Yes & \\
\hline 16 & 0 & 33 & 11 & Yes & Yes & \\
\hline 10 & 8 & 20 & 20 & Yes & Yes & \\
\hline 13 & 6 & 14 & 23 & Yes & No & \\
\hline 33 & 16 & 23 & 5 & Yes & No & \\
\hline 30 & 31 & $\mathbf{F}$ & $\mathbf{F}$ & Yes & Yes & \\
\hline 8 & 0 & 8 & 0 & No & No & \\
\hline 10 & 0 & 18 & 4 & Yes & No & \\
\hline 11 & - & 22 & - & No & - & (Died) \\
\hline 10 & 0 & 14 & 10 & Yes & Yes & \\
\hline 34 & 24 & 23 & 28 & Yes & Yes & \\
\hline 49 & 58 & 18 & 26 & Yes & Yes & \\
\hline 18 & 7 & 45 & 29 & Yes & Yes & \\
\hline
\end{tabular}

three daily puffs of terbutaline, while she was taking metoprolol $50 \mathrm{mg}$ twice daily. One-and-a-half years later she was considered to be in functional group I. Investigation at this time (Fig. 2; Table 3) showed an almost normal systolic myocardial function with an LVEDD of $5.2 \mathrm{~cm}$, an EF of 0.53 , an LVET of 95 per cent, a normal left atrium of $3.3 \mathrm{~cm}$, and no pathological extra sounds.

\section{CASE 24}

This was a 48-year-old woman who was well until January 1976 when she developed exertional dyspnoea and peripheral oedema. The cardiac volume was $650 \mathrm{ml} / \mathrm{m}^{2}$. She was treated with digoxin and frusemide, and her dyspnoea increased slowly. She was referred to this centre in September 1976. Investigations showed an LVEDD of $7 \cdot 1$ with mechanical alternans, an EF of 0.12 and 0.35 in alternate beats, an LVET of 65 per cent, and loud extra sounds. She was admitted to our hospital on 27 September. On admission she had no dyspnoea at rest but could not walk even on the flat. Auscultation showed a tachycardia of 120 beats/min, third and fourth heart sounds, but no systolic murmur. The blood pressure was $130 / 90 \mathrm{mmHg}$ and the heart size $760 \mathrm{ml} / \mathrm{m}^{2}$. Investigations showed (Table
3) an LVEDD of $7.4 \mathrm{~cm}$, an EF of 0.30 with tiny contractions, and an LVET of 66 per cent. She was considered to have very severe COCM. Cardiac catheterisation showed a heart rate of 122 , an arterial pressure of $128 / 100 \mathrm{mmHg}$, a pulmonary artery pressure of $59 / 35 \mathrm{mmHg}$, and a right atrial pressure of $16 \mathrm{mmHg}$; the cardiac index was $1.6 \mathrm{l}$ / min per $\mathrm{m}^{2}$ and stroke index $13 \mathrm{ml} / \mathrm{m}^{2}$. After $15 \mathrm{mg}$ metoprolol intravenously, the corresponding pressures were $108 / 83,47 / 30$, and $14 \mathrm{mmHg}$, the cardiac index was $1 \cdot 3$, and the stroke index 12 . She was therefore given metoprolol orally $25 \mathrm{mg}$ twice daily in addition to digitalis and frusemide. A distinct improvement was noted with a reduction in her dyspnoea. The blood pressure was unchanged, the heart rate decreased to 90 to 100 beats/min, and the extra sounds became much quieter. The metoprolol dosage was increased to $50 \mathrm{mg}$ twice daily, and the patient improved further so that she could walk freely without discomfort. On 20 October she developed left-sided chest pain and was noted to have a temperature for two days. She showed no clinical signs of heart failure thereafter.

Nine days later the patient was found dead. Necropsy disclosed a dilated heart of $550 \mathrm{~g}$. The coronary arteries showed no stenosis and there were no signs of myocardial ischaemia. Two small pulmonary emboli were found.

\section{Non-invasive findings}

Forty-six studies were performed before, and 53 after, the start of beta-receptor blockade in 23 patients. Four patients were not reinvestigated before they died (cases 9, 11, 12, and 24) and one patient (case 5) was not investigated before the start of treatment. The observation period was divided into four parts; 1 to 6,7 to 12,13 to 24 , and greater than 24 months after the start of beta blockade. If a patient underwent more than one investigation during the same period, the mean values were taken. The results are shown in Fig. 3 and 4.

From Fig. 3A and Table 3 it can be seen that the LVEDD decreased in 12 patients. In three patients the LVEDD increased (cases 3,6, and 8), and in 11 patients it remained essentially unchanged. The EF (Fig. 3B) increased in 10 patients, decreased slightly in three (cases 18,19, and 27), and was unchanged in five. The overall increase in the EF during the first six months was $0.32 \pm 0.02$ to 0.42 $\pm 0.04(p<0.05)$. In the seven patients in whom the EF could be measured before and after two years of treatment, it increased from $0.31 \pm 0.05$ to $0.52 \pm 0.05(\mathrm{p}<0.01)$. The mean $\mathrm{V}_{\mathrm{CF}}$ was calcu- 
lated before and after the start of treatment in 16 patients. As can be seen from Fig. 3C an increase occurred in seven patients and a decrease in two (cases 16 and 18) while in seven patients it remained unchanged. The LVET increased in seven patients, decreased in two (cases 21 and 27), and remained unchanged in the others (Fig. 3D).

The amplitude of the third heart sound, measured from the apical phonocardiogram, decreased in most patients (Fig. 4A). However, three of the patients (cases 18, 21, and 27) showed an increase. Overall, the amplitude of the third heart sound decreased from $11 \pm 2$ to $5 \pm 1 \mathrm{~mm}(\mathrm{p}<0.02)$ and the amplitude of the fourth heart sound showed similar changes, with a decrease in 12 patients and an unchanged or increased amplitude in four patients (Fig. 4B). The $\mathrm{RFW} / \mathrm{H}$ ratio decreased significantly overall in all observation periods (Fig. 4C). During the first six months the RFW/H ratio decreased from $19 \pm 3$ to $10 \pm 4$ per cent

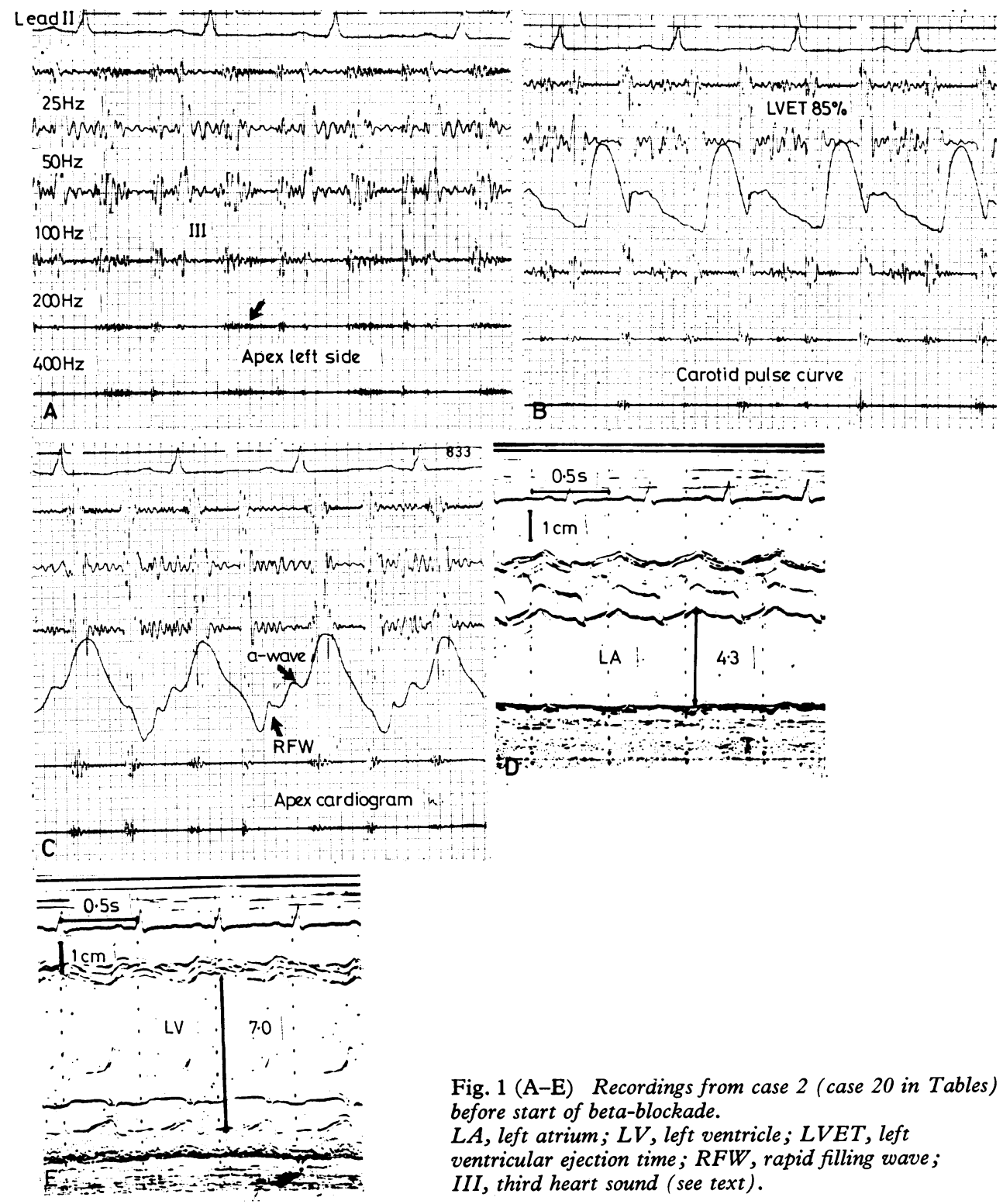


$(\mathrm{p}<0.01)$. Only one patient showed an increase during this time (case 27) and two patients had essentially unchanged $\mathrm{RFW} / \mathrm{H}$ ratios (cases 15 and 21 ). The $\mathrm{a} / \mathrm{H}$ ratio decreased significantly during the first six months $(\mathrm{p}<0.05)$. Two patients showed an increase in the $\mathrm{a} / \mathrm{H}$ ratio (cases 19 and 27) and in five patients it was unchanged (cases 1 , $4,8,18$, and 26) (Fig. 4D).

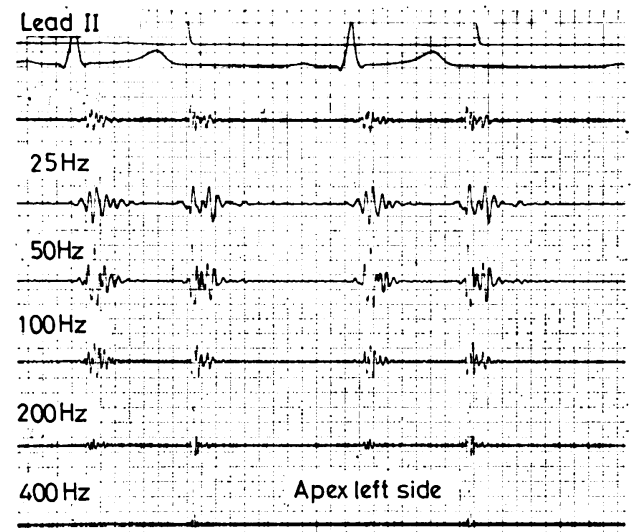

A
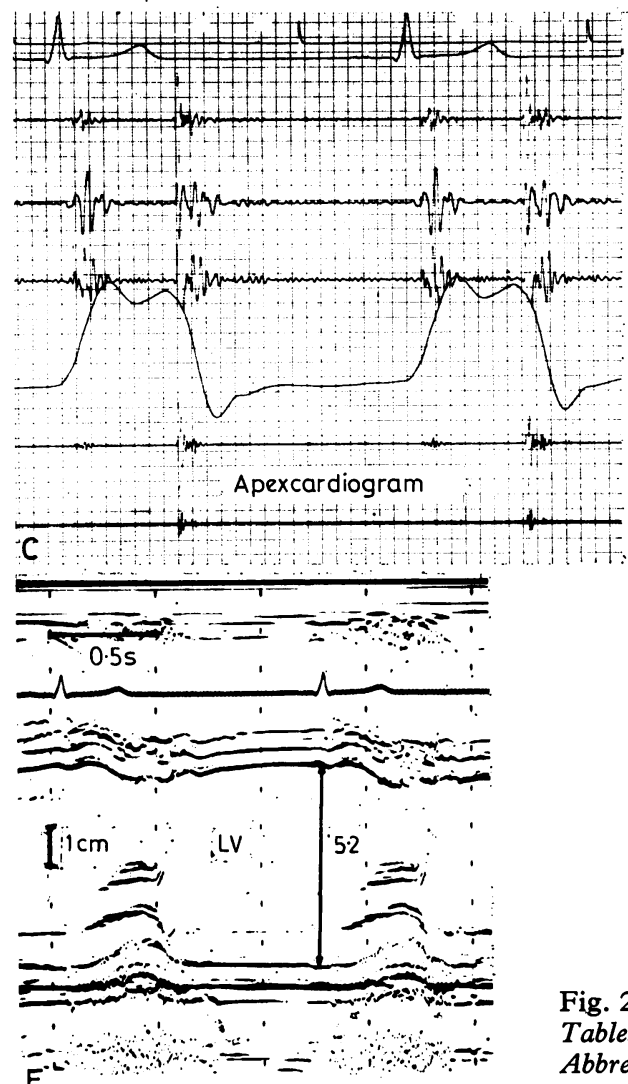

Fig. 2 (A-E) Recordings from case 2 (case 20 in Tables) one-and-a-half years after start of beta-blockade. Abbreviations as in Fig. 1 (see text).
The pronounced improvement in the $\mathrm{EF}$ was related to a reduction of the third heart sound amplitude or the RFW (cases 1, 7, 16, and 17). In most cases, the LVET increased at the same time. The increase in the EF was, in most cases, related to a reduction of LVEDD. In some cases this reduction was not observed, indicating a change in the degree of mitral regurgitation (case
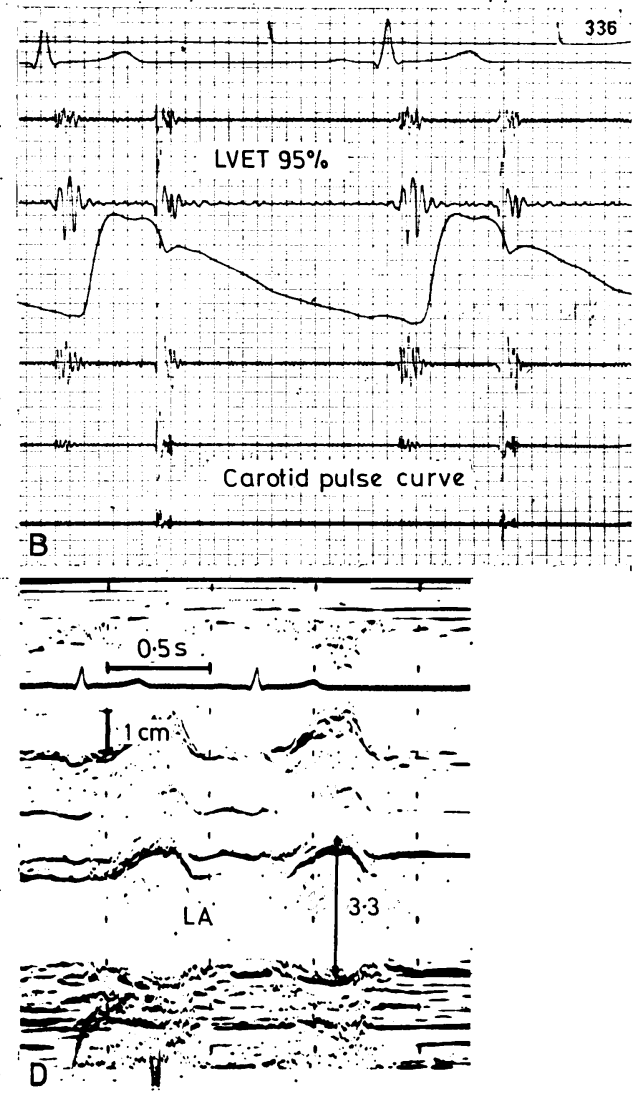
LVEDD

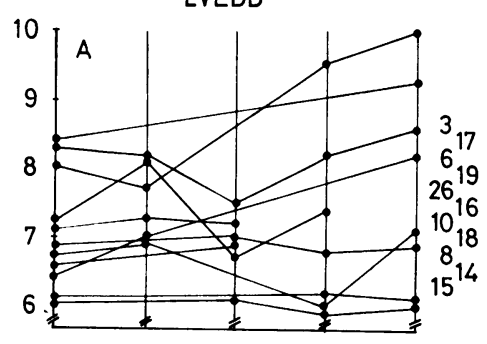

E

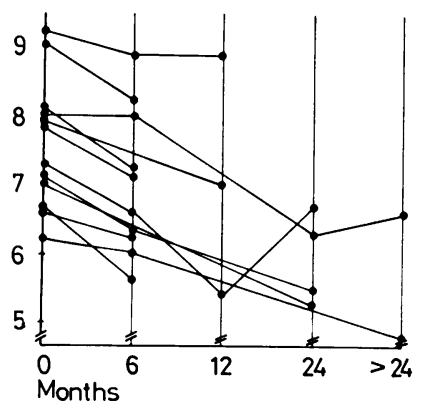

Mean $\mathrm{V}_{\mathrm{CF}}$

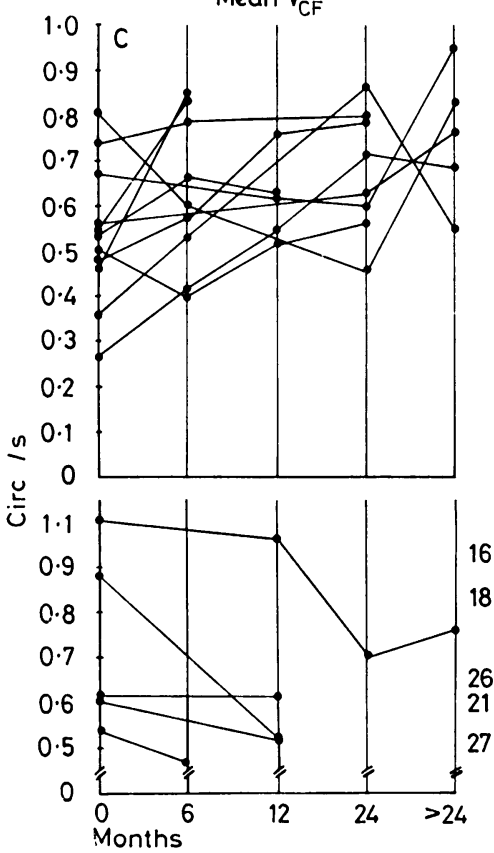

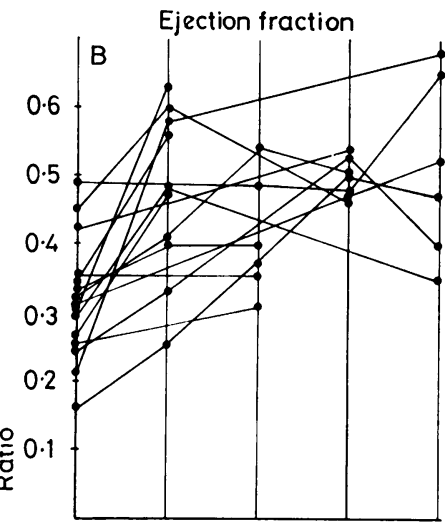

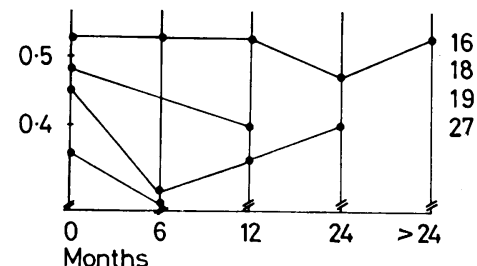

है

Fig. 3 (A-D) and 4 (A-D) Haemodynamic variables before and during treatment with beta-blockers. The treatment period is divided into four parts : 0 to 6, 7 to 12, 13 to 24, and $>24$ months. Each period is represented by $a$ vertical line. Investigations performed during a period are shown by a dot on that line. If more than one investigation was carried out, the mean values are shown. Values for each individual patient are connected. The upper part of each figure shows patients who have increased values, the lower part patients who have decreased values for each variable. Patients with unchanged values lie in between. On the right are the case numbers referring to Table 1. The position of the number corresponds to the dots on the left vertical line. For exact values, see Table 3. 
17). The third heart sound amplitude and the RFW always showed corresponding changes. A reduction of these variables correlated with an improvement in the clinical condition and this occurred usually in the first two weeks. This correlation can be seen in the comparison of changes in functional groups (Table 2 and Fig. 4A-D). In three patients (cases 18, 21, and 27) the EF and LVET were either unchanged or reduced and the third heart sound and RFW increased. Cases 18 and 21 complained of gastrointestinal discomfort and showed poor motivation for treatment. They had no problems with the medication during inpatient treatment, but their compliance as outpatients was questionable. Case 27 deteriorated during the first four months on metoprolol $50 \mathrm{mg}$ twice a day. On

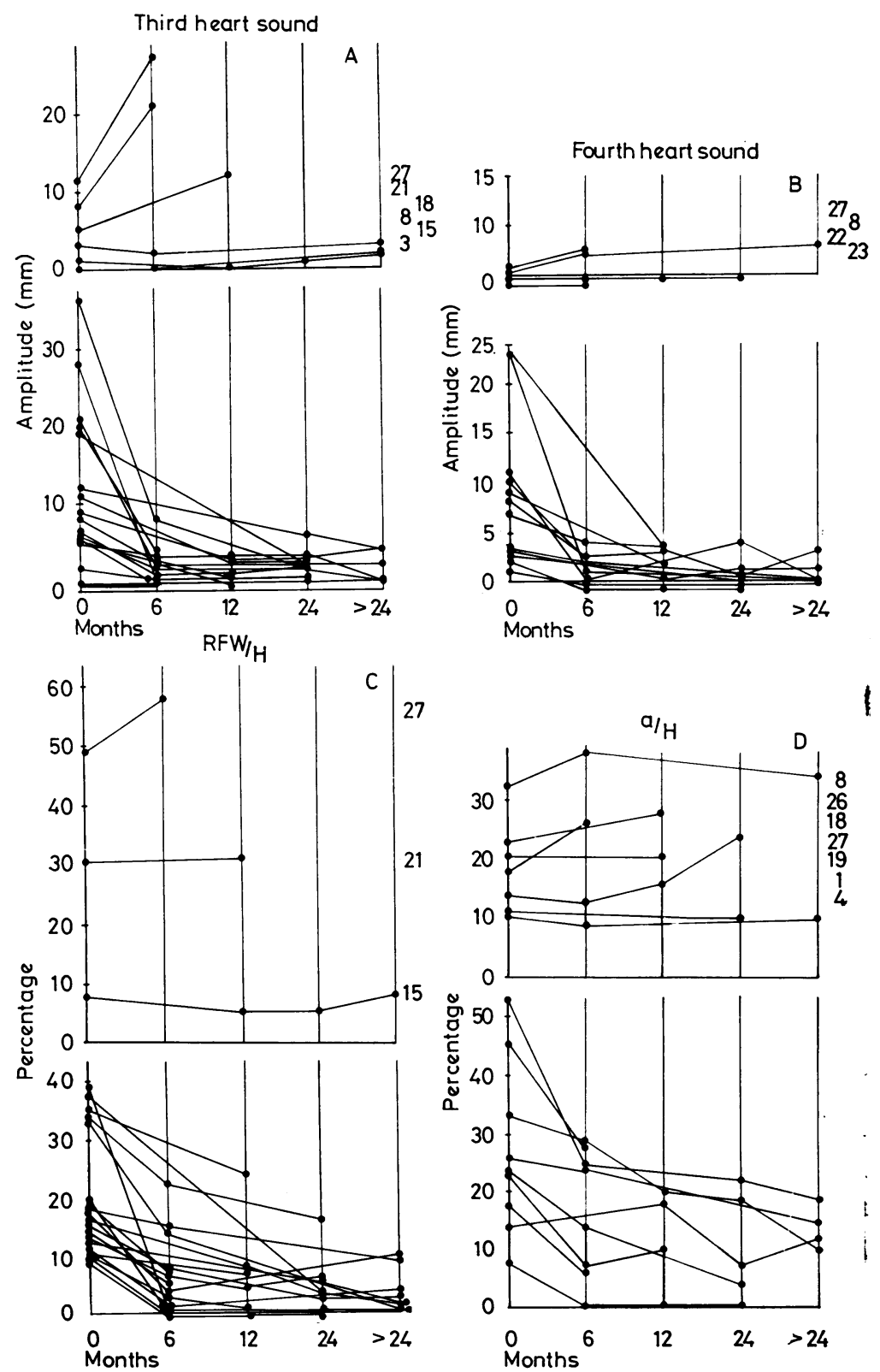

Fig. 4 
investigation four months after the start of betablockade, the third heart sound had increased to $50 \mathrm{~mm}$ and the RFW/H ratio to 110 per cent (sic) while the EF was reduced from 0.29 to $0 \cdot 19$. The patient's clinical condition became critical and he developed severe peripheral oedema which did not respond to increased doses of frusemide. In desperation, the metoprolol dosage was increased to $100 \mathrm{mg}$ twice a day. The patient improved dramatically in the following two weeks, peripheral oedema and dyspnoea at rest disappearing. Further investigation showed that the third heart sound was then reduced to $5 \mathrm{~mm}$ and the $\mathrm{RFW} / \mathrm{H}$ ratio to 6 per cent. The mean values for the last two studies, both performed within six months of the start of beta-blockade, are shown in Table 3 and Fig. 3 and 4 . The figures do not illustrate the observed changes in this patient.

The relation of heart rate to the other variables in Fig 3 and 4 was analysed. Mean values from all studies before and during treatment have been used. No correlation was found between the reduction in heart rate induced by beta-blockade and changes in $\mathrm{EF}, \mathrm{LVET}, \mathrm{RFW} / \mathrm{H}$, or $\mathrm{a} / \mathrm{H}$ ratios. Before treatment there was a weak correlation between heart rate and third heart sound amplitude $(\mathrm{r}=0.59 ; \mathrm{n}=22)$ but this disappeared during treatment. The reduction in third heart sound amplitude correlated weakly with the heart rate change $(r=0.59)$ (Fig. 6).

\section{HEART VOLUME}

Chest $x$-ray film was taken in all patients before and in 21 patients during beta-blocker treatment. The heart volumes are shown in Fig. 5A. The volume decreased significantly in eight patients, with a distinct increase in three patients. The remaining 10 patients showed no definite changes. In the two patients with the largest hearts, a distinct reduction was seen.

\section{EXERCISE TESTS}

Dynamic exercise tests were performed in 22 patients before the start of treatment. Four patients were bed-ridden and were not exercised at this time, but two were investigated during follow-up. The pretreatment load was arbitrarily recorded as 40 watts, which was the lowest corresponding value from the other patients. The 13 patients in the upper part of Fig. 5B increased their exercise capacity from $91 \pm 12$ to $117 \pm 10$ watts $(p<0.01)$. The post-exercise heart rate was significantly lower at six months $(p<0.01)$. The work pulse after exercise increased by 19 per cent, from $37 \pm 3$ to $43 \pm 3$ joules/beat $(p<0.02)$. Systolic blood
Fig. 5 (A) Radiological heart volume in $\mathrm{ml} / \mathrm{m}^{2}$ before and during treatment with beta blockers. (B) Maximum workload (watts) before and during treatment with beta-blockers. The upper part of each figure shows patients who have increased values; the lower part, patients who have decreased values.
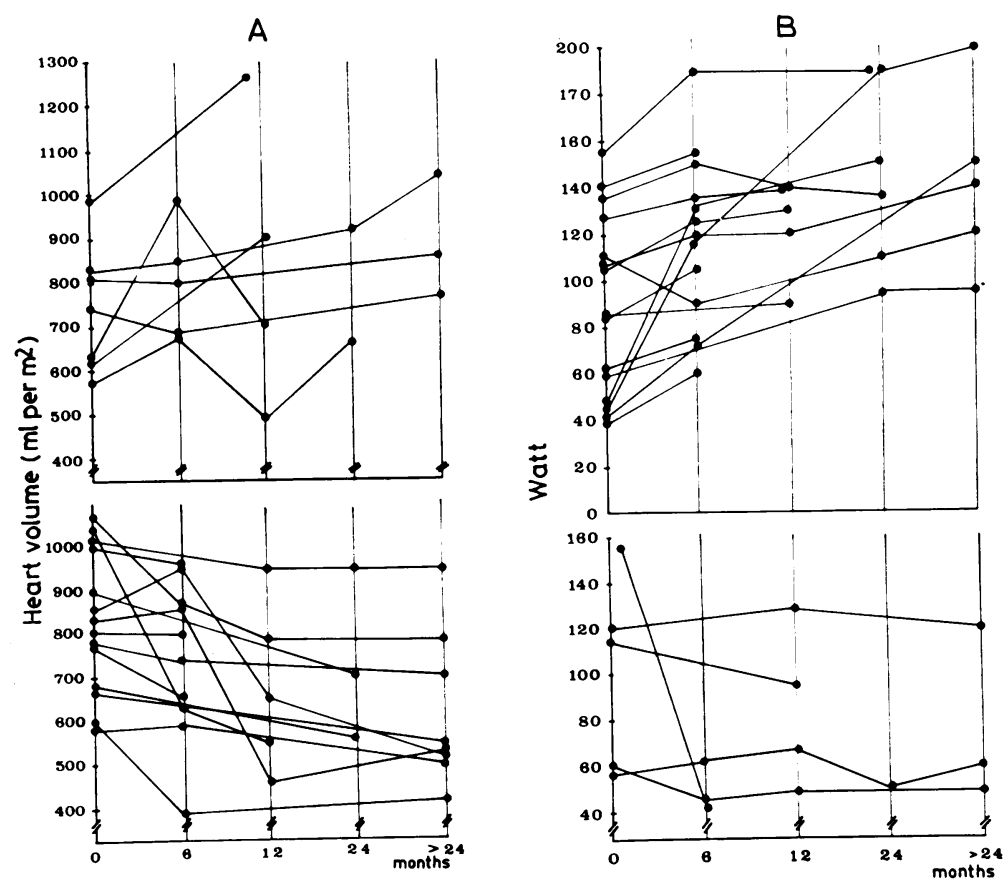
pressure showed no significant changes during rest or exercise.

\section{Invasive investigation}

Mainly non-invasive techniques were used in this study for the diagnosis of COCM and assessment of the severity of the disease and the results of treatment. However, in four of the first patients treated, cardiac catheterisation was performed on two occasions, separated by an interval of two to 13 months (cases 1, 2, 6, and 7). These investigations formed part of the routine clinical assessment and were not related to the study design. The results, however, support the findings from the non-invasive investigations (Fig. 7). Cardiac output increased in three of these four patients and this was especially pronounced in case 1 who showed an increase from 1.9 to $5.1 \mathrm{l} / \mathrm{min}$. The heart rate was reduced in all patients but one. The stroke volume increased conspicuously in three of the patients and pulmonary artery diastolic pressure was reduced in three. A distinct reduction in systemic vascular resistance was seen in case 1 , in whom the most obvious increase in cardiac output occurred. The brachial artery and systolic blood pressure increased in all patients.

In nine patients left ventricular angiography and echocardiography were performed within a space of one week. The EF calculated from these investigations correlated well ( $r=0.92)$ (Fig. 8).

\section{Discussion}

All the patients in this study were diagnosed as having congestive cardiomyopathy, according to the criteria proposed by Goodwin and Oakley. ${ }^{\text {? }}$ Coronary artery disease was excluded by history, and by coronary angiography in 14 patients. The diagnosis and the assessment of the severity of the disease were based upon a series of non-invasive investigations which included phonocardiograms, apex cardiograms, pulse curves from the carotid artery, jugular vein, and liver, and echocardiograms. The advantages of this non-invasive programme were that it gave information on the severity of myocardial dysfunction and that it could be repeated several times during follow-up. Measure-

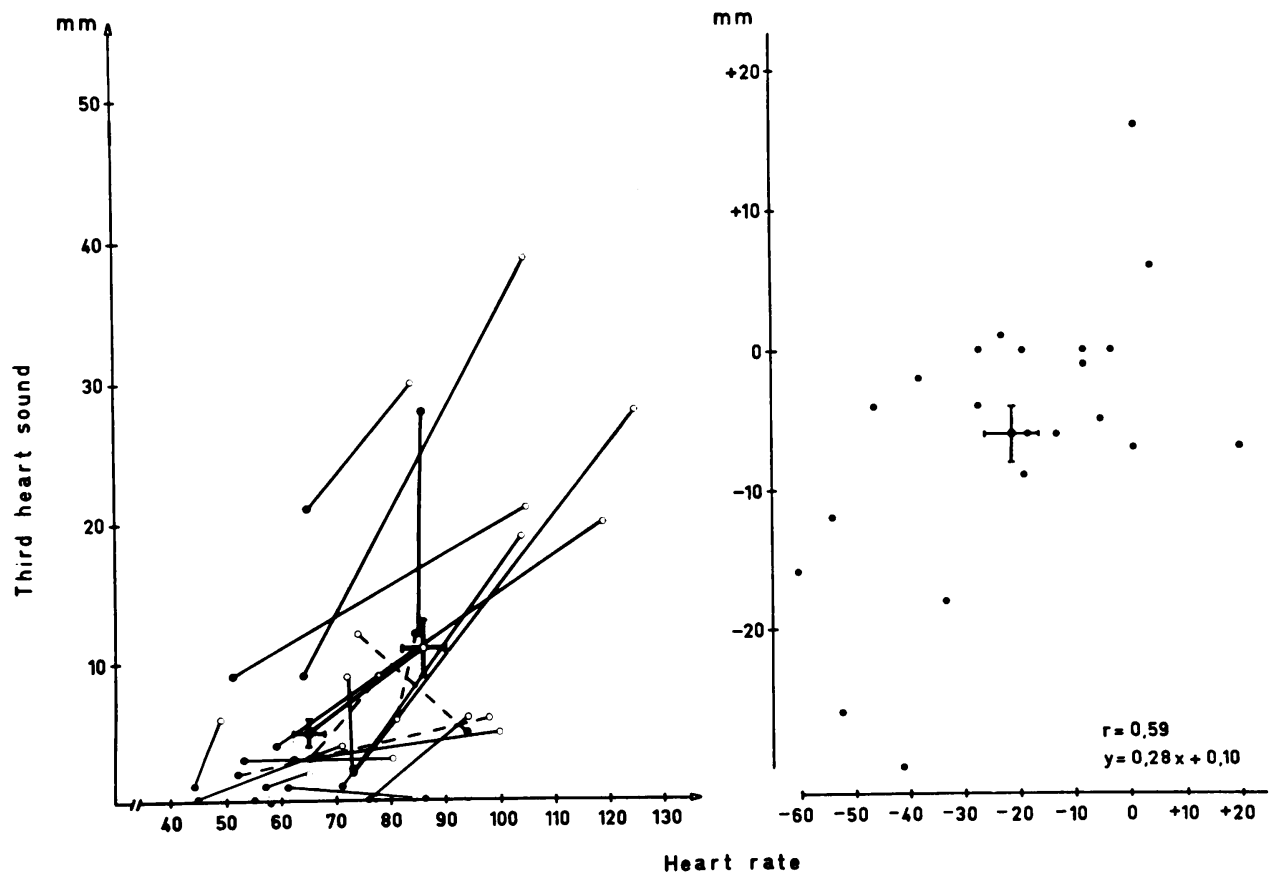

Fig. 6 Relation between heart rate and amplitude of third heart sound, before $(O)$ and during (O) treatment with beta-blockers. The left-hand side of the figure shows absolute changes, and the right-hand side shows changes in heart rate and third heart sound amplitude during treatment compared with control values. Values during treatment are mean values of all observations. Interrupted lines refer to patients with atrial fibrillation. 
ment of the variables LVEDD, EF, mean $\mathrm{V}_{\mathrm{CF}}$, LVET, third and fourth heart sounds, "a" wave, and $\mathrm{RFW} / \mathrm{H}$ made it possible to grade myocardial dysfunction, allowing the identification of subgroups within this population of patients with generalised left ventricular myocardial disease. Of the 28 patients included in this study, 24 were considered to have severe myocardial dysfunction, and four less severe dysfunction. It is known that the prognosis is poor for patients with COCM and symptoms of heart failure despite optimal treatment with digitalis and diuretics. The mortality in the 24 patients with severe failure was 17,34 , and 48 per cent after one, two, and three years, respectively. In a comparable group of 13 patients with COCM who were treated at this centre without beta blockers, the mortality was 54,81 , and 90 per cent after one, two, and three years, respectively. ${ }^{14}$ It is known that survival of patients with heart disease is generally related to myocardial function, and the prognosis worsens with increasingly severe heart failure. ${ }^{215-17}$ It is therefore possible that an improvement in myocardial function with chronic beta-blockade could improve the prognosis. Another possible protective effect might be by prevention of ventricular fibrillation. It is known from animal experiments that, at least in ischaemic heart disease, beta-blockers reduce the incidence of ventricular fibrillation. ${ }^{18}$ In three studies in postinfarction patients, improved survival has been reported with beta-blockers given for two years after the acute illness. ${ }^{19-21}$ The effects of beta-blockade on myocardial function, however, were not investigated in any of those studies. Beta-blockade might prevent sudden cardiac death through mechanisms quite independent of any effect on myocardial systolic function.

In this study 28 patients were treated with betablockers for six to 62 months except for four patients who died within two months. All patients also received unchanged or reduced doses of digitalis and diuretics during this treatment period. It was necessary to introduce beta-blockade slowly as otherwise dyspnoea tended initially to increase. As assessed by the clinical findings, myocardial function improved in 15 patients, while in 12 it remained unchanged and in one it deteriorated. All eight patients in functional group IV (New York Heart Association criteria) had pronounced capacitylimiting dyspnoea. One patient died from progressive cardiac failure, despite withdrawal of treatment, whereas myocardial function was improved in the others as assessed by non-invasive investigations and clinical evaluation. The improvement was most obvious during the first month. Three of these patients, initially in functional group IV, went back to work. Of the patients in functional group III, seven were much improved by treatment while 11 were unchanged and one deteriorated. The observations from this study are in agreement with the results in seven patients reported earlier. ${ }^{6}$ In the 16 patients given placebo before the start of treatment, myocardial function was either unchanged or deteriorated. The improvement $\boldsymbol{A}$ of
Fig. 7 Haemodynamic findings before and two to 13 months after the start of beta-blockade in four patients with congestive cardiomyopathy (case no. 1, 3, 6, and 7).

$P A_{D}$, pulmonary artery diastolic pressure; $B$, before and $A$, after start of beta-blockade.
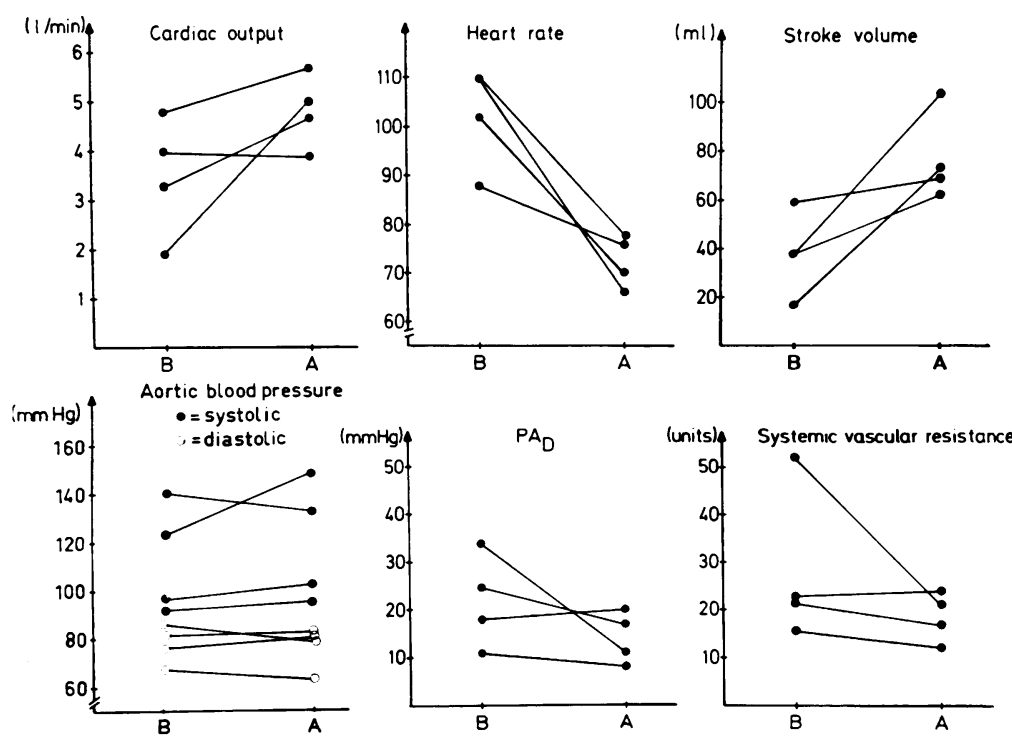


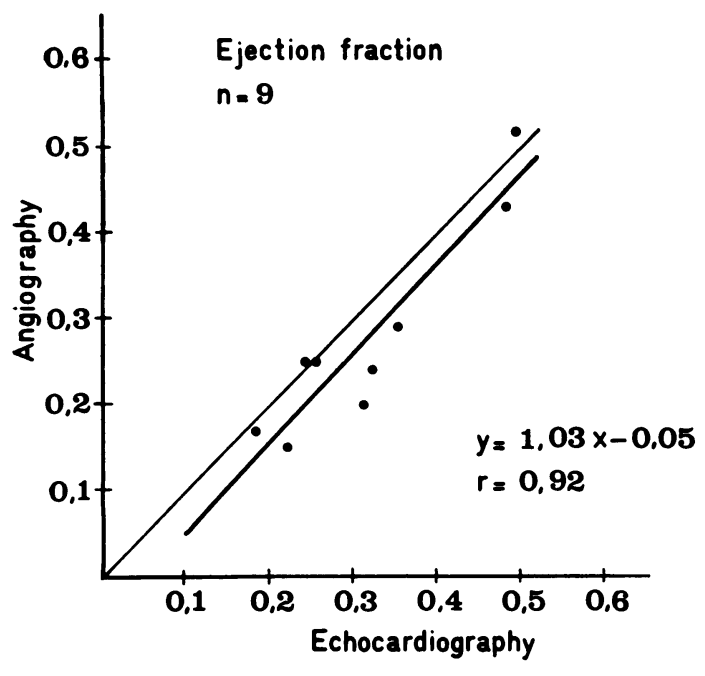

Fig. 8 Ejection fraction calculated from left ventricular angiograms and echocardiograms. In each patient the investigations were performed within one week.

myocardial function which occurred after the start of beta-blockade was very clear and cannot be considered to be a spontaneous change independent of treatment. The response to beta-blockade was very variable and it was not possible to predict the effects of treatment from initial clinical findings or investigations. The results of the pilot study ${ }^{6}$ suggested that patients with a higher heart rate responded better to beta-blockade. This was not confirmed in this study. The reduction of heart rate did not correlate to the change in EF, LVET, $\mathrm{RFW} / \mathrm{H}$, or $\mathrm{a} / \mathrm{H}$ ratios. However, patients with severe heart failure usually do have a tachycardia. If it is myocardial disease per se that is influenced by beta-blockade, the selection of patients by heart rate could be misleading. Patients with an LVEDD $>7 \mathrm{~cm}$ have a lower one-year mortality if treated with the addition of beta-blockade than those with conventional treatment. ${ }^{14}$ It seems that in most patients the beneficial effects of beta-blockade occur within one to three months of the start of treatment, and that the improvement is stable thereafter. Some patients, however, continue to improve for a longer time (cases 1, 17, and 20). The improvement of myocardial function produced by beta-blockade was shown in this study as an improvement of functional class and exercise capacity, and by the improved results of non-invasive investigations. Systolic as well as diastolic myocardial function improved, and the changes included a reduction of LVEDD, an increased EF and LVET, a reduced amplitude of third and fourth heart sounds, and a reduction in the rapid filling wave and "a" wave.
An increase in LVET, EF, and mean $V_{C F}$ represents an improvement in myocardial systolic function. As mentioned earlier, the degree of secondary mitral regurgitation is important for the evaluation of $\mathrm{EF}$ and mean $\mathrm{V}_{\mathrm{CF}}$. An increase in these variables can occur with increased mitral regurgitation but indicates improved myocardial systolic function in combination with an increase in LVET and/or the disappearance of an apical systolic murmur. Changes in heart sounds, the rapid filling wave, and the " $a$ " wave corresponded to changes in left ventricular distensibility induced by beta-blockade. Changes in the third heart sound and RFW were frequently related and were useful early indicators of the therapeutic effect. It has been reported that beta blockade in patients with ischaemic heart disease causes an increase in left ventricular distensibility as well as increased left ventricular enddiastolic volume. ${ }^{22}$ In this study, however, there was no increase in LVEDD. In contrast, it often decreased, with signs of improved diastolic function.

The improvement in cardiac function and in the patients' general condition with beta-blockade could not be explained on the basis of spontaneous improvement in selected subjects. All patients referred to this centre suspected of having COCM have been investigated and all those in whom the diagnosis was confirmed were included in the study. Only patients with evidence of grossly impaired myocardial function (generally in functional group III or IV, according to the New York Heart Association criteria) were given chronic betablocker treatment. In a separate study, ${ }^{13}$ the effect of withdrawal of beta-blockade has been investigated in 13 of the patients reported here. It was found that withdrawal of treatment caused a deterioration of myocardial function and in several of the patients led to a distinct exacerbation of their symptoms. This strongly supports the view that the improvement seen in the patients in this study is related to the beta-blocker treatment.

Phaeochromocytoma may induce cardiomyopathy with heart failure, ${ }^{23}{ }^{24}$ clearly showing a connection between high concentrations of catecholamines and this condition. In the treatment of these patients, beta-blocking agents are used to protect the myocardium from the influence of catecholamines until the tumour is removed sugically. ${ }^{25}$ Furthermore, prolonged bed rest has been found to cause an improvement in patients with COCM after three to 12 months, ${ }^{5}$ possibly because bed rest causes a reduction of cardiac work and a lower level of sympathetic activity. If this is the case, similar mechanisms may be involved in the beneficial effects of long-term bed rest and chronic beta-blockade. Animal experiments have shown 
that the spontaneous hereditary congestive cardiomyopathy of Syrian hamsters can be counteracted by beta-blockade. ${ }^{26}{ }^{27}$ I-ong-term treatment of rats with catecholamines has been found to cause diffuse myocardial degeneration as well as hypertrophy. ${ }^{28}$ Thus, it may be concluded that other clinical observations, besides our own, together with animal data, support the hypothesis that catecholamines are involved in the development of some forms of cardiomyopathy and that reduced sympathetic activity by beta-receptor blockade can prevent the progress of the condition. This view is supported by our present findings of a beneficial effect of chronic beta blockade on COCM. The suggested role of catecholamines and sympathetic activity in the development of the condition remains to be proved, and studies are in progress to find out whether there is primary sympathetic overactivity in patients with COCM or an increased sensitivity to sympathetic stimulation.

This study clearly demonstrates that chronic beta-receptor blockade may cause a significant improvement in myocardial function and relief of symptoms in patients with COCM. The improvement occurs in patients with moderate as well as severe heart failure. The patients responding best to beta-blockade could not be predicted by the methods used and it is therefore suggested that beta-receptor blockade should be added to conventional treatment with digitalis and diuretics in all patients with COCM. More experience of this treatment regimen, however, is needed in order to allow identification of the patients most suitable for it.

This investigation has been supported by grants from the Swedish Medical Research Council, the Swedish National Association against Heart and Chest Diseases, and Göteborg Medical Society.

\section{References}

${ }^{1}$ Hamby RI. Primary myocardial disease. A prospective clinical and hemodynamic evaluation in 100 patients. Medicine 1970; 49: 55-78.

${ }^{2}$ Kreulen TH, Gorlin R, Herman MV. Ventriculographic patterns and hemodynamics in primary myocardial disease. Circulation 1973; 47: 299-308.

${ }^{3}$ Hess OM, Turina J, Goebel NH, Krayenbühl HP. Klinischer Verlauf der kongestiven Kardiomyopathie. Schweiz Med Wochenschr 1976; 106: 1577-9.

${ }^{4}$ Kübler W, Zebe H, Mäurer W, Mehmel H, Zekl G. Die kongestive Kardiomyopathie. Munch Med Wochenschr 1976; 118: 751-8.

${ }^{5} \mathrm{McD}$ onald CD, Burch GE, Walsh JJ. Prolonged bed rest in the treatment of idiopathic cardiomyopathy. Am $\mathcal{F}$ Med 1972; 52: 41-50.
${ }^{6}$ Waagstein F, Hjalmarson $\AA$, Varnauskas E, Wallentin I. Effect of chronic beta-adrenergic receptor blockade in congestive cardiomyopathy. Br Heart $\mathcal{F} 1975 ; 37$ : 1022-36.

${ }^{7}$ Goodwin JF, Oakley CM. The cardiomyopathies. $\mathrm{Br}$ Heart $\mathcal{F} 1972$; 34: 545-52.

${ }^{8}$ Wikstrand J, Nilsson K, Wallentin J. Distortion of non-invasive cardiac pulse curves. A capillary-damped pick-up and a calibration unit for apexcardiograms and other pulse curves. Br Heart $\mathcal{F}$ 1977; 39: 995-1005.

${ }^{9}$ Meiners S. Messmethoden zur Analyse der Herz- und Kreislaufdynamik. Freiburger Colloquium, München, 1958: 84-98.

${ }^{10}$ Willems J, Kesteloot $H$. The left ventricular ejection time. Its relation to heart rate, mechanical systole and some anthropometric data. Acta Cardiol (Brux) 1967; 22: 401-25.

11Pombo JF, Troy BL, Russell RO Jr. Ventricular volumes and ejection fraction by echocardiography. Circulation 1971; 43: 480-90.

${ }^{12}$ Cooper RH, O'Rourke RA, Karliner JS, Peterson KL, Leopold GR. Comparison of ultrasound and cineangiographic measurements of the mean rate of circumferential fiber shortening in man. Circulation 1972 ; 46: 914-23.

${ }^{13}$ Swedberg $\mathrm{K}$, Hjalmarson $\AA$, Waagstein F, Wallentin I. Adverse effects of beta blockade withdrawal in patients with congestive cardiomyopathy. $\mathrm{Br}$ Heart f 1980; 44: 134-42.

${ }^{14}$ Swedberg K, Hjalmarson $\AA$, Waagstein F, Wallentin I. Prolongation of survival in congestive cardiomyopathy by beta-receptor blockade. Preliminary communication. Lancet $1979 ; 1$ : $1374-6$.

${ }^{15}$ Feild BJ, Baxley WA, Russell RO Jr, et al. Left ventricular function and hypertrophy in cardiomyopathy with depressed ejection fraction. Circulation 1973; 47: 1022-31.

${ }^{16}$ Vedin A, Wilhelmsen L, Wedel H. Prediction of death and reinfarction after initial myocardial infarction. Acta Med Scand 1977; 201 : 309-16.

${ }^{17}$ Loogan F, Kuhn H. Classification and natural history of primary cardiomyopathies. In : Riecker $G$, Weber A, Goodwin J, eds. Myocardial failure. Berlin: Springer, 1977: 232-50.

${ }^{18}$ Corr PB, Witkowski FX, Sobel BE. Mechanisms contributing to malignant dysrhythmias induced by ischemia in the cat. $\mathcal{F}$ Clin Invest 1978; 61: 109-19.

${ }^{19}$ Ahlmark G, Saetre H, Korsgren M. Reduction of sudden deaths after myocardial infarction. Lancet 1974; 2: 1563.

${ }^{20}$ Wilhelmsson C, Vedin JA, Wilhelmsen L, Tibblin G, Werkö L. Reduction of sudden deaths after myocardial infarction by treatment with alprenolol. Lancet 1974; 2: 1157-64.

${ }^{21}$ Multicentre International Study. Improvement in prognosis of myocardial infarction by long-term betaadrenoreceptor blockade using practolol. $\mathrm{Br} \mathrm{Med} \mathcal{f}$ 1975; 3: 735-40.

${ }^{22}$ Coltart DJ, Alderman EL, Robison SC, Harrison DC. Effect of propranolol on left ventricular function, segmental wall motion, and diastolic pressure-volume relation in man. Br Heart $\mathcal{f} 1975$; 37: 357-64. 
${ }^{23}$ Kline IK. Myocardial alterations associated with pheochromocytomas. Am F Pathol 1961; 38: 539-47.

${ }^{24}$ Engelman K, Sjoerdsma A. Chronic medical therapy for phaeochromocytoma. Ann Intern Med 1964; 61: 230-41.

${ }^{25}$ Baker G, Zeller NH, Weitzner S, Leach JK. Pheochromocytoma without hypertension presenting as cardiomyopathy. Am Heart $\mathcal{f} 1972$; 83: 688-93.

${ }^{26}$ Jasmin G, Bajusz E. Polymyopathie et cardiomyopathie héréditaire chez le hamster de Syrie. Inhibition sélective des lésions du myocarde. Ann Anat Pathol (Paris) 1973; 18: 49-66.

${ }^{27}$ Lossnitzer K, Janke J, Hein B, Stauch M, Flecken- stein A. Disturbed myocardial calcium metabolism: a possible pathogenetic factor in the hereditary cardiomyopathy of the Syrian hamster. Recent Adv Stud Cardiac Struct Metab 1975; 6: 207-17.

${ }^{28}$ Källfelt BJ, Waldenström AP, Hjalmarson ÅC. Effects of adrenaline in vivo on protein synthesis, mechanical performance and sensitivity to ischemia in the perfused rat heart. $\mathcal{f}$ Mol Cell Cardiol 1977; 9: 383-98.

Requests for reprints to Dr Karl Swedberg, Department of Medicine, East Hospital, S-416 85 Göteborg, Sweden. 